\title{
CENÁRIOS E PERSPECTIVAS DE POLÍTICAS PÚBLICAS DA EDUCAÇÃO ESPECIAL NO BRASIL
}

\author{
Ricardo Antonio Gonçalves Teixeira ${ }^{1}$ \\ Ana Flávia Teodoro de Mendonça Oliveira² \\ Andréia da Silva Quintanilha Sousa ${ }^{3}$
}

\section{RESUMO}

Este artigo está dividido em duas partes, no primeiro momento discute os aspectos históricos-normativos da educação especial no Brasil desde as primeiras iniciativas de institucionalização implementadas no período imperial até os dias atuais. No segundo momento, mapeia por meio de levantamento e da exploração dos dados extraídos do Censo escolar, INEP, de 1998 a 2016, o total de matrículas na educação especial em escolas especializadas e classes especiais, por etapas e modalidade de ensino. A pesquisa pode ser classificada como do tipo exploratória, cuja principal finalidade é proporcionar uma visão geral do cenário da educação especial no Brasil. As "fronteiras" de uma política pública são sempre suscetíveis de serem postas em questão, através de um processo constante de redefinição dos limites dos campos políticos e do contexto histórico de cada época, como nos alertam Muller e Surel (2001). Assim, para o século XXI, o atendimento às pessoas com deficiência é empreendido com base no novo modelo denominado inclusivo no qual a ideia defendida é a de que não é a pessoa com deficiência que deve se adaptar à escola, mas as instituições escolares que devem ser capazes de oferecer condições de acesso e permanência para todos.

Palavras-chave: Políticas Públicas. Educação Especial. Matrículas.

\footnotetext{
1 Doutor em educação pela Faculdade de Educação da Universidade Federal de Goiás (UFG). Professor na Faculdade de Educação e no Programa de Pós-Graduação em Educação da UFG. E-mail: professorricardoteixeira@gmail.com

2 Doutora em Educação pela Universidade Federal de Pernambuco. Atualmente é professora adjunta da Universidade Federal de Goiás no curso de Pedagogia. E-mail: anaflavia_teodoro@hotmail.com

3 Doutora em Educação pela Universidade Federal do Rio Grande do Norte (UFRN). Atualmente é professora associada da Universidade Federal de Rondônia lotada no Departamento de Fundamentos e Política da Educação da UFRN. E-mail: andreia_quintanilha_sousa@hotmail.com
} 


\title{
SCENARIO AND PERSPECTIVES OF PUBLIC POLICY OF SPECIAL EDUCATION IN
}

BRAZIL

\begin{abstract}
This article is divided in two parts, in the first moment it discusses the historicalnormative aspects of the special education in Brazil from the first initiatives of institutionalization implemented in the imperial period until the present day. In the second moment it maps, by means of a survey and the exploitation of the data extracted from the school census, INEP, from 1998 to 2016, the total enrollment in special education in specialized schools and special classes, by stages and teaching modality. The research can be classified as exploratory type whose main purpose is to provide an overview of the scenario of special education in Brazil. The "frontiers" of a public policy are always susceptible of being questioned, through a constant process of redefining the limits of political fields and the historical context of each epoch, as Muller and Surel (2001) warn us. Thus, for the 21 st century, care for people with disabilities is undertaken on the basis of the new so-called inclusive model whose idea is that it is not the disabled person who must adapt to the school, but the school institutions that must be capable to offer conditions of access and permanence for all.
\end{abstract}

Keywords: Public Policies. Special Education. Enrollment.

ESCENARIO Y PERSPECTIVAS DE POLÍTICA PÚBLICA DE LA EDUCACIÓN ESPECIAL

EN BRASIL

\section{RESUMEN}

Este artículo está dividido en dos partes, en el primer momento discute los aspectos histórico-normativos de la educación especial en Brasil desde las primeras iniciativas de institucionalización implementadas en el período imperial hasta los días actuales. En el segundo momento, a través del levantamiento y de la explotación de los datos extraídos del Censo escolar, INEP, de 1998 a 2016, el total de matrículas en la educación especial en escuelas especializadas y clases especiales, por etapas y modalidad de enseñanza. La investigación puede ser clasificada como del tipo exploratorio cuya principal finalidad es proporcionar una visión general del escenario de la educación especial en Brasil. Las "fronteras" de una política pública son siempre susceptibles de ser cuestionadas, a través de un proceso constante de redefinición de los límites de los campos políticos y del contexto histórico de cada época, como nos alertan Muller y Surel (2001). Así, para el siglo XXI, la atención a las personas con discapacidad es emprendida con base en el nuevo modelo denominado inclusivo cuya idea defendida es la de que no es la persona con discapacidad que debe adaptarse a la escuela, sino las instituciones escolares que deben ser capaces de ofrecer condiciones de acceso y permanencia para todos.

Palabras clave: Políticas Públicas. Educación Especial. Inscripción. 


\section{INTRODUÇÃO}

No Brasil, a partir da Carta Magna de 1988, uma série de marcos regulatórios para a educação especial, na perspectiva inclusiva, vão sendo proclamados. Podemos citar como exemplo o Estatuto da Criança e do Adolescente (Lei no 8.069/90); a Lei de Diretrizes e Bases da Educação (Lei n ${ }^{\circ}$ 9.394/96); o Plano Nacional de Educação 2001-2010 (Lei no 10.172/2001), bem como o Plano Nacional da Educação 2014-2024 em vigor (Lei $\mathrm{n}^{\circ}$ 13.005/2014).

Assim, dentre as metas prevista pela Lei $n^{\circ} 13.005 / 2014$ para a superação das desigualdades educacionais e a erradicação de todas as formas de discriminação está a meta 4, que trata da Educação Especial/Inclusiva e estabelece a universalização do acesso à educação básica e ao atendimento educacional especializado "para a população de 4 a 17 anos com deficiência, transtornos globais do desenvolvimento e altas habilidades ou superdotação", preferencialmente na rede regular de ensino" (PNE, 2014).

Esse "novo modelo denominado inclusivo" passa a defender a ideia de que "não é a pessoa com deficiência que deve se adaptar à escola, mas esta é que deve se ajustar, oferecendo-Ihe condições para que possa usufruir do ambiente escolar, avançando em sua aprendizagem e socialização", como aponta Martins (2015, p. 216).

A Política Nacional de Educação Especial na Perspectiva da Educação Inclusiva defende que essa educação se realize por meio do Atendimento Educacional Especializado (AEE). Contudo, apesar do AEE ser indicado como o meio para o aluno da educação especial receber seu atendimento, apenas $37,6 \%$ das matrículas dessa população estão no AEE, em 2017, conforme dados do INEP/MEC (2018) e apenas $43 \%$ dos professores do AEE possuem formação específica para atuarem na Educação especial conforme Censo Escolar da Educação Básica (INEP, 2018).

Entender as políticas para a educação especial na perspectiva da inclusão como uma disputa travada em contexto histórico-social, por sujeitos sociais, significa admitir que políticas públicas são um constructo social 
complexo e contraditório, com sentido de luta, de embate, que convive necessariamente com seu contrário, mas que se estabelece na direção de superar práticas sociais baseadas na desigualdade, embora sem garantias, pois a sociedade capitalista está alicerçada na exclusão e na desigualdade.

Nesse sentido, realizar uma pesquisa exploratória com a finalidade de proporcionar uma visão geral das políticas públicas para a educação especial no Brasil exige que se tenha a clareza de que as "fronteiras" de uma política pública são sempre suscetíveis de serem postas em questão, através de um processo constante de redefinição dos limites dos campos políticos e do contexto histórico de cada época.

Pensar a realidade social por contradição é perseguir e refletir a respeito da relação existente entre inclusão e exclusão não como algo gerado fora das práticas sociais, mas, necessariamente, como apresenta Lunardi (2001), pensar a realidade como duas faces de uma mesma moeda, cujos processos sociais, políticos e econômicos estão em um processo constante de redefinição de acordo com o contexto histórico e social.

É importante salientar que o período focalizado por essa pesquisa no tocante ao levantamento e à exploração dos dados extraídos do Censo escolar, para a educação especial, revelam que a partir de 2006 o total de matrículas em escolas da rede regular ascendeu significativamente: de 43.923, em 1998 para 79.6486, em 2016. O maior percentual de estudantes está nos anos iniciais do Ensino Fundamental (45,7\%) e o menor em Educação profissional (0,8\%) (INEP, 2016).

As políticas públicas para educação especial estão articuladas às proposições para o setor educacional como um todo, apesar de disporem de normatizações e orientações específicas. Os aspectos históricosnormativos e conceituais são elementos importantes de reflexão para compreender a política nacional de inclusão escolar, políticas que podem ser visualizadas através dos dados disponibilizados no Censo da Educação Escolar/INEP.

Com a finalidade de dar maior visibilidade ao cenário das políticas públicas para a educação especial no Brasil, este artigo está dividido em 
duas partes. A primeira parte apresenta os aspectos históricos-normativos da educação especial no Brasil desde as primeiras iniciativas de institucionalização implementadas no período imperial até os dias atuais. A segunda parte traz o levantamento e as análises dos dados extraídos do Censo escolar, INEP, de 1998 a 2016 referente às matrículas em escolas especializadas e escolas regulares. Por fim, tecemos nossas considerações finais.

\section{ASPECTOS HISTÓRICOS-NORMATIVOS DA EDUCAÇÃO ESPECIAL NO BRASIL}

As primeiras iniciativas de institucionalização do atendimento educacional às pessoas com deficiência no Brasil remontam ao período imperial com a criação, pelo Imperador Dom Pedro II, do Imperial Instituto dos Meninos Cegos, via Decreto Imperial $n^{\circ}$ 1.428/1854. Nesse marco legal, estão contidos os fins do Instituto (instrução primária, educação moral e religiosa, ensino musical, alguns ramos de instrução secundária e os de ofícios fabris, conforme artigo 1), a organização da instituição, as funções de cada profissional envolvido na formação do "meninos cegos", bem como quais seriam as "matérias de ensino, exames e prêmios" (Capítulo IV). O Instituto não poderia admitir "os menores de 6 anos, e maiores de 14; os escravos" (Art. 25), sendo gratuito aos que "forem reconhecidamente pobres" (Art.19).

O Imperial Instituto dos Meninos Cegos passa a denominar-se Instituto Nacional dos Cegos por meio do Decreto n 193/1890; em 1891 modifica novamente a nome para Instituto Benjamin Constant (IBC), em homenagem ao ministro do recém-criado Ministério da Instrução, Correios e Telégrafos, Benjamim Constant, por meio do Decreto 1.320/1891.

O regulamento do IBC incluía disciplinas científicas, mas sua ênfase era o ensino profissional. Tal profissionalização era defendida como forma de garantir a subsistência do aluno e de sua família, abrangendo, sobretudo, as profissões manuais como "torneiro, charuteiro, cigarreiro, empalhador [...] predominava o que já vinha sendo valorizado para a educação das camadas populares" (JANNUZZI, 2012, p. 22-23). 
Ainda no período Imperial, foi criado o Imperial Instituto de SurdosMudos (ISM), por meio da Lei $n^{\circ} 839 / 1857$. Somente teriam acesso ao ISM os homens. Na República recebeu o nome de Instituto Nacional de SurdosMudos e a partir de 1957 transformou-se no Instituto Nacional de Educação de Surdos (INES), considerado um centro nacional de referência.

Assim, no início da República, são ainda o IBC e o INES as instituições privilegiadas e focos de atenção do poder central, pois contavam com verbas do governo federal. Ressalta-se, porém, que não se tratava de uma educação para todas as pessoas com cegueira ou surdez, como mencionado, O acesso era restrito: O IBC recebia somente estudantes na faixa etária de 6 a 14 anos e, no INES, somente os homens poderiam ser admitidos.

No tocante à educação de pessoas com deficiência intelectual, Jannuzzi (2012, p. 24-33) expõe que o número de instituições aumenta a partir de 1920, momento que a vertente médico-pedagógica busca respostas ao desafio apresentado pelos casos de pessoas com essa deficiência, na época apontada como mais graves. Nesse contexto, os médicos percebem "a importância da pedagogia" criando instituições escolares ligadas a hospitais psiquiátricos, mantendo "a segregação desses deficientes", mas com a "percepção da importância da educação", que passa a ser vista como um campo de conhecimento que teria o desafio de integrá-los, a partir de uma "prática social mais ampla".

Em 1947, surgiram as campanhas nacionais de educação de adultos promovidas pelo governo federal. No I Congresso de Educação de Adultos, foi lançada a Campanha de Educação de Adolescentes e Adultos (CEAA). Em 1949, o Seminário Internacional de Educação de Adultos contou com o auxílio financeiro da Organização dos Estados Americanos (OEA) e da Organização das Nações Unidas para a Educação, a Ciência e a Cultura (UNESCO). Tentativas de minimizar a situação precária que a educação popular se encontrava. O analfabetismo, em 1940, estava na casa dos $56 \%$, em 1959,50,5\% e, em 1960, na ordem de $39,4 \%$, conforme apresenta Jannuzzi (2012, p. 74). 
Embora houvesse críticas a campanhas como forma de desenvolver a educação popular, "o setor governamental, sob a influência de elementos do ensino especializado, de associações civis, inclusive deficientes como a dos cegos vai promover a área através de campanhas" (JANNNUZZI, 2012, p. 75).

Assim, a partir de 1950, por meio das campanhas, o governo demonstra interesse com a área da educação das pessoas com deficiência. São elas: Campanha de Educação do Surdo Brasileiro (CESB) - Decreto $n^{\circ}$ 42.728, de 3 de dezembro de 1957; Campanha Nacional de Educação e reabilitação dos deficitários visuais (CNERDV) - Decreto $n^{\circ} 44.136$ de $1^{\circ}$ de agosto de 1958 e a Campanha Nacional de Educação e Reabilitação de Deficientes mentais' ${ }^{1}$ (CADEME) - Decreto $n^{\circ} 48.961$, de 22 de setembro de 1960.

De fato, com a instituição da CADEME, foi criado um fundo especial, alimentado por dotações e contribuições da União, Estados e Municípios, na ordem pública, e de demais entidades paraestatais e de economia mista com previsão de donativos e fundos de contribuições de ordem financeira e patrimonial. Mazzotta (2005) afirma que as diretorias executivas da CADEME foram administradas, em sua maioria, e por longos períodos, pelos presidentes da APAE e Pestalozzi.

Com recursos financeiros, patrimoniais e força política, tais instituições passam a ser consideradas essenciais e de utilidade pública, sendo seus atendimentos considerados indispensáveis ao estado.

Essas campanhas visavam ampliar os centros de treinamento e reabilitação das pessoas com deficiência em todo território nacional. Grande parte das instituições que anunciavam ações educativas se constituíam de clínicas e serviços particulares no campo médico-hospitalar, composto por profissionais do campo da saúde (MAZZOTTA, 2005).

Tais campanhas, na perspectiva de Jannuzzi (2012, p. 75), foram implantadas como uma forma de o governo minimizar os gastos públicos, uma vez que "aceitava voluntariado, verba vinda de donativos nacionais e estrangeiros ou de serviços prestados pela própria campanha", o que 
reforça a ideia de que a educação para essa camada da população ainda era precária e tímida.

O presidente Juscelino Kubitschek (1956-1961) reconhece que cabe do governo "cuidar do ensino desses indivíduos entregues às campanhas filantrópicas, uma vez que nesse momento existiam 12 mil cegos no país, incluindo $40 \%$ de crianças em idade escolar". O único estabelecimento oficial especializado possuía capacidade para 300 alunos levando em consideração os convênios firmados com administrações estaduais (JANNUZZI, 2012, p. 81).

A nova Constituição de 1946 reafirmou propostas de redemocratização do país e assegurou à União a competência de legislar sobre as Leis de Diretrizes e Bases da Educação (LDB). Assim, em 1961, é instituída a Lei de Diretrizes e Bases da Educação Nacional (LDB), por meio da Lei $n^{\circ}$ 4.024/1961, que contempla um tópico específico sobre a "educação de excepcionais".

O art. 88 expõe que a "educação de excepcionais, deve, no que for possível, enquadrar-se no sistema geral de educação, a fim de integrá-los na comunidade"; o art. 89 reforça a possibilidade de investimento público nas instituições de "iniciativa privada consideradas eficientes pelos conselhos estaduais, podendo receber dos "poderes públicos tratamento especial mediante bolsas de estudo, empréstimos e subvenções" a fim de garantir atendimento aos alunos "excepcionais". Esses artigos foram revogados pela LDB vigente, a Lei $n^{\circ}$ 9.396/96, que será abordada mais detalhadamente a seguir.

Duas importantes instituições brasileiras especializadas em deficiência, mais especificamente na deficiência intelectual, são: a Sociedade Pestalozzi (fundada em 1926) e a Associação de Pais e Amigos de Excepcionais (APAE) (fundada em 1954). Essas sociedades, com o tempo, ampliam seus serviços para todo o território nacional, ganham força e espaço no âmbito político.

Com a criação do Centro Nacional de Educação Especial (CENESP), órgão ligado ao então Ministério da Educação e Cultura, via Decreto n. $72.425 / 1973$, passam a ser extintas as campanhas nacionais vigentes, dentre 
as quais a CADEME, revertendo os acervos financeiros e patrimoniais à CENESP (art. 10).

A história da CENESP, destituída em 1986, contou com três diretorias, dentre as quais, duas assumidas por presidentes da Pestalozzi (primeira diretoria de 1973 a 1979 e terceira diretoria de 1983 a 1986).

A década de 1970 foi marcada pelos movimentos internacionais de apoio a pessoas com deficiência. Em 1971, a Organização das Nações Unidas (ONU) proclama a Declaração dos Direitos do Deficiente Mental, com foco em proteção dos seus direitos, dentre os quais "instrução e formação". Em 1975, é proclamada a Declaração dos Direitos da Pessoa com Deficiência, Resolução n 3.447/1975, oficialmente instituída, no Brasil, via Emenda Constitucional n 12/1978, que estabelece, em parágrafo único, os seguintes preceitos:

É assegurado aos deficientes a melhoria de sua condição social e econômica especialmente mediante: I - educação especial e gratuita; II - assistência, reabilitação e reinserção na vida econômica e social do país; III - proibição de discriminação, inclusive quanto à admissão ao trabalho ou ao serviço público e a salários; IV possibilidade de acesso a edifícios e logradouros públicos.

De acordo com Teixeira (2010), tal emenda só é contemplada dez anos mais tarde, no art. 227, parágrafo segundo, com complemento no art. 244, da Constituição Federal do Brasil de 1988 (CF/1988).

Com a instituição da Lei n 5.692/1971, além da deficiência intelectual, o atendimento especial é estendido aos alunos com deficiência física e altas habilidades no contexto de escolarização desde que os alunos atendessem as normas fixadas pelos Conselhos de Educação, conforme art. $9^{\circ} \mathrm{da}$ referida Lei (BRASIL, 1971).

A década de 1970 é marcada como um período de transição de um modelo segregacionista (isolamento social da pessoa com deficiência) ao movimento integracionista (com foco na institucionalização como preparo para a vida). O pressuposto integracionista indicado no campo da educação sugeria a convivência harmônica da pessoa com deficiência na sociedade. Para tanto, era necessário um preparo. Assim, desde pequenas, 
as crianças eram encaminhadas para instituições especializadas em deficiência para se adaptarem à sociedade (realizar tarefas do cotidiano e adquirir e ofícios do mundo do trabalho), sendo a escola um importante espaço para tais conquistas.

Acerca da atenção especial proposta nesse período, Mazzotta (2005) ressalta o cuidado sobre a avaliação das ações ditas educacionais. Para ele, "uma análise mais cuidadosa revela tratar-se de situações organizadas com outros propósitos que não o educacional" (p. 15) e complementa, "sob o título de Educação de Deficientes encontram-se registros de atendimentos ou atenção com vários sentidos: abrigo, assistência, terapia etc. Daí dever revestir-se de extremo cuidado a seleção das medidas e ações educacionais destinadas aos deficientes" (p. 17). Assim, prevalece, mesmo sob a égide de educação, na década de 1970 (estendendo até meados da década de 1980), o modelo clínico, terapêutico e assistencial da educação especial no Brasil.

De acordo com Teixeira (2010), no Brasil, na década de 1970, instituições filantrópicas como as APAEs e Pestalozzi introduzem um modelo educacional às margens do ensino regular. Para Bueno (1993, p. 99),

\begin{abstract}
A educação especial que nasce sobre a bandeira da ampliação de oportunidades educacionais aos que fogem da normalidade, na medida em que não desvela os determinantes sócio-econômicoculturais que subjazem às dificuldades de integração do aluno diferente, na escola e na sociedade, serve de instrumento para a legitimação de sua segregação.
\end{abstract}

No Brasil, a década de 1980 foi marcada por um período de conquistas: fim do regime militar, crescimento dos movimentos sociais organizados, uma nova Constituição (CF/1988), que, além dos direitos civis e políticos, contempla os direitos sociais e humanos.

A ONU (Organização das Nações Unidas), no ano de 1981, declara o ano internacional da pessoa com deficiência a partir do lema "igualdade de oportunidades para todos".

A educação na CF/1988 é tratada como um direito de todos e dever do estado e da família, visando garantir o pleno desenvolvimento da pessoa, 
- exercício da cidadania e a qualificação para o trabalho (art. 205), devendo ser ofertado em igualdade de condições para o acesso e permanência na escola, liberdade no ensinar e aprender, pluralismo de ideias e concepções, gratuidade e qualidade (art. 206).

Sobre os aspectos educacionais relativos à pessoa com deficiência, para além dos direitos e garantias fundamentais de que todos são iguais perante a lei (art. $5^{\circ}$ ), constitui-se como dever do estado garantir a educação da pessoa com deficiência, preferencialmente, na rede regular de ensino (art. 208).

Com base nos preceitos do art. 208, segundo Almeida e Teixeira (2011, p. 157),

O termo "preferencialmente", além de polêmico, dá margem a
variadas interpretações. Frentes ligadas às instituições especializadas
que oferecem ensino especial embasam-se nesses argumentos,
segundo suas explicações, para a prática de ensino, mesmo não
sendo escola. Outros, porém, fundamentam-se na ideia do
complemento de atividades escolares. [...] há ainda correntes que
defendem a tese de que o termo "preferencialmente" enquadra-se
em casos bastante específicos, como o de uma criança em
processo de internação em longo prazo, ou com complicações
médicas ou, ainda, com doença infecto-contagiosa que, nesses
casos, a impede de frequentar a escola por um determinado
período.

Em 1989, por meio da Lei n 7.853 , é criada a Coordenadoria Nacional para Integração da Pessoa com Deficiência (Corde), que estabelece normas gerais para o exercício dos direitos individuais e sociais para a efetiva integração social das pessoas com deficiência.

As políticas educacionais brasileiras no campo da educação especial, até então destinada à pessoa com deficiência, é fortemente impulsionada pelos movimentos externos ocorridos na década de 1990. Destacam-se a Conferência Mundial de Educação para Todos, realizada em Jomtien, Tailândia, 1990, e a Declaração de Salamanca, decorrente da Conferência Mundial de Educação Especial, ocorrida na Espanha, em 1994.

Em 1990, é instituído, no Brasil, o Estatuto da Criança e do Adolescente (ECA) por meio da Lei no 9.069/1990, um importante documento legal que traz garantias a um público até então desassistido por políticas específicas. 
No campo da educação, reforça os preceitos constitucionais da responsabilidade da família para a obrigação em matricular seus filhos em escolas da rede regular de ensino (art. 55), com base na garantia da igualdade no acesso e da permanência na escola (art. 53), proposta pela Declaração de Jomtien (1990).

Em 1994, o então Ministério da Educação e Desporto aprova a Política Nacional de Educação Especial, que reafirma os pressupostos construídos a partir de padrões homogêneos de participação e aprendizagem. Assim, a Política não provoca uma reformulação das práticas educacionais de maneira que sejam valorizados os diferentes potenciais de aprendizagem no ensino comum, "mas mantém a responsabilidade da educação desses estudantes exclusivamente no âmbito da educação especial" (BRASIL, 2008).

Em 1996, é instituída uma nova LDB, por meio da Lei n 9.394/1996, em consonância com a Constituição Federal de 1988. O art. 59 apresenta a necessidade de assegurar, aos estudantes: currículo, método, recursos e organização específicos no sentido de atender as necessidades dos educandos; terminalidades específicas às pessoas com deficiência que não alcançaram os níveis exigidos para conclusão do ensino fundamental, bem como aceleração escolar dos alunos superdotados; professores com especialização necessária para integração dos educandos da educação especial em classes comuns. Visa também, em seu art. 37, assegurar aos educandos "que não puderam efetuar seus estudos na idade regular, oportunidades educacionais apropriadas, consideradas as características do alunado, seus interesses, condições de vida e de trabalho, mediante cursos e exames".

Somente em 1999, a Declaração de Salamanca tem seu reflexo exposto na nova política de educação especial do MEC, denominada de Política Nacional da Pessoa Portadora de Deficiência, instituída por meio do Decreto $n^{\circ} 3.298 / 1999$.

Essa nova política, embora com nomenclatura destinada a pessoas com deficiência, amplia sistematicamente o público de atenção no campo da educação especial, em conformidade com o proposto pela Declaração 
de Salamanca. De acordo com o art. 24, em seu parágrafo primeiro, "Entende-se por educação especial, para os efeitos deste Decreto, a modalidade de educação escolar oferecida preferencialmente na rede regular de ensino para educando com necessidades educacionais especiais, entre eles o portador de deficiência". Como consequência dessa política, vários atendimentos passam a ter atenção, a exemplo, dentre outros, das classes hospitalares.

Como forma de regulamentar a política, em 2001, o MEC institui as Diretrizes Nacionais para a Educação Especial, por meio da Resolução CNE/CEB $n^{\circ} 2 / 2001$. No art. $1^{\circ}$, parágrafo único, consta que o atendimento escolar da pessoa com deficiência se dará na educação infantil, nas creches e pré-escolas, assegurando-Ihes os serviços de educação especial sempre que se evidencie, mediante avaliação e interação com a família e a comunidade, a necessidade de atendimento educacional especializado. No art. $2^{\circ}$, expõe que os sistemas de ensino devem matricular todos os alunos. As escolas devem organizar-se para o atendimento aos educandos com necessidades educacionais especiais, assegurando as condições necessárias para uma educação de qualidade para todos.

O Decreto n 3. 956/2001 "promulga a Convenção Interamericana para a Eliminação de Todas as Formas de Discriminação contra as Pessoas Portadoras de Deficiência". Essa Convenção foi adotada na cidade da Guatemala pela Assembleia Geral da OEA (Organização dos Estados Americanos), em 7 de junho de 1999, assinada pelo Brasil, que passa a ser "Estado parte", e ratificada em 15 de agosto de 2001.

Em termos de bases legais no campo da educação especial, enquanto na década de 1990 tem-se os principais marcos políticos e concepções instituídos, a primeira década dos anos 2000, para além dos referendos expostos, apresenta diversas frentes de direitos no campo educacional, conforme se apresenta no Quadro 1. 
Quadro 1 - Bases legais sobre educação especial no Brasil, primeira década dos anos 2000

\begin{tabular}{|c|c|c|}
\hline Ano & Marco legal & Síntese \\
\hline 2000 & Lei $n^{\circ} 10.098$ & $\begin{array}{l}\text { Estabelece normas gerais para promoção e acessibilidade de } \\
\text { pessoas com deficiência, apresenta definição do entendimento } \\
\text { legal do que vem a ser deficiência, expõe sobre demandas de } \\
\text { tecnologias assistivas e desenho universal. }\end{array}$ \\
\hline 2001 & $\begin{array}{l}\text { Decreto Lei } n^{\circ} \\
3.956\end{array}$ & $\begin{array}{l}\text { Promulga a Convenção Interamericana para a Eliminação de } \\
\text { Todas as Formas de Discriminação contra as Pessoas Portadoras } \\
\text { de Deficiência. }\end{array}$ \\
\hline 2001 & Lei $n^{\circ} 10.172$ & $\begin{array}{l}\text { Aprova o Plano Nacional de Educação, com duração de dez } \\
\text { anos, que destaca que "o grande avanço que a década da } \\
\text { educação deveria produzir seria a construção de uma escola } \\
\text { inclusiva que garanta o atendimento à diversidade humana" }\end{array}$ \\
\hline 2002 & Lei $n^{\circ} 10.436$ & $\begin{array}{l}\text { Reconhece a Língua Brasileira de Sinais (LIBRAS) como meio legal } \\
\text { de comunicação e expressão. }\end{array}$ \\
\hline 2002 & Portaria $n^{\circ} 2.678$ & $\begin{array}{l}\text { Aprova o projeto da Grafia Braille para a Língua Portuguesa e } \\
\text { recomenda o seu uso em todo o território nacional. }\end{array}$ \\
\hline 2002 & $\begin{array}{l}\text { Resolução } \\
\text { CNE/CP n } 1\end{array}$ & $\begin{array}{l}\text { Institui as Diretrizes Curriculares Nacionais para a Formação de } \\
\text { Professores da Educação Básica, em nível superior, definindo a } \\
\text { necessidade de prever, em sua organização curricular, a } \\
\text { formação docente enquanto componente de atenção à } \\
\text { diversidade, contemplando, em suas bases, conhecimentos } \\
\text { sobre as especificidades de alunos com necessidades } \\
\text { educacionais especiais. }\end{array}$ \\
\hline 2003 & Portaria $n^{\circ} 3.284$ & $\begin{array}{l}\text { Versa sobre requisitos de acessibilidade às pessoas com } \\
\text { deficiências, para instruir processos de autorização e de } \\
\text { reconhecimento de cursos, e de credenciamento de instituições. }\end{array}$ \\
\hline 2004 & Lei $n^{\circ} 10.845$ & $\begin{array}{l}\text { Institui o Programa de Complementação ao Atendimento } \\
\text { Educacional Especializado às Pessoas com Deficiência. }\end{array}$ \\
\hline 2004 & Decreto $n^{\circ} 5.296$ & $\begin{array}{l}\text { Regulamenta as leis } n^{\circ} 10.048 / 00 \text {, que dá prioridade de } \\
\text { atendimento às pessoas que especifica, e } n^{\circ} 10.098 / 00 \text {, que } \\
\text { estabelece normas gerais e critérios básicos para a promoção } \\
\text { da acessibilidade das pessoas portadoras de deficiência ou com } \\
\text { mobilidade reduzida, e implementa o Programa Brasil Acessível. }\end{array}$ \\
\hline 2005 & Decreto $n^{\circ} 5.626$ & $\begin{array}{l}\text { Regulamenta a Lei no } 10.436 / 2002 \text {, que dispõe sobre a LIBRAS, e o } \\
\text { art. } 18 \text { da Lei no } 10.098 / 2000 \text {, apresentando, dentre outros, a } \\
\text { LIBRAS enquanto disciplina curricular obrigatória nos cursos de } \\
\text { formação de professores (licenciaturas) e cursos de } \\
\text { fonoaudiologia e curricular optativa nos demais cursos } \\
\text { educação superior e na educação profissional. }\end{array}$ \\
\hline 2006 & $\begin{array}{l}\text { Plano Nacional } \\
\text { de Direitos } \\
\text { Humanos }\end{array}$ & $\begin{array}{l}\text { Plano constituído em parceria entre a Secretaria Especial dos } \\
\text { Direitos Humanos, Ministério da Educação, Ministério da Justiça e } \\
\text { UNESCO, visando fomentar, no currículo da educação básica, } \\
\text { temáticas sociais ligadas a ações afirmativas que possibilitem } \\
\text { inclusão, acesso e permanência na educação superior. }\end{array}$ \\
\hline 2006 & Portaria $n^{\circ} 976$ & $\begin{array}{l}\text { Dispõe sobre os critérios de acessibilidade aos eventos do } \\
\text { Ministério da Educação, conforme Decreto n } 5.296 / 2004 \text {. }\end{array}$ \\
\hline 2007 & $\begin{array}{l}\text { Plano de } \\
\text { Desenvolvimento } \\
\text { da Educação } \\
\text { (PDE) }\end{array}$ & $\begin{array}{l}\text { Estabelece como foco a aprendizagem, apresentando como } \\
\text { eixo para fortalecer a inclusão educacional das pessoas com } \\
\text { deficiência, abordando aspectos como acessibilidade, } \\
\text { implantação de salas de recursos multifuncionais e a formação } \\
\text { docente para o atendimento educacional especializado. }\end{array}$ \\
\hline 2007 & Decreto n 6.094 & $\begin{array}{l}\text { Apresenta o compromisso do Plano de Metas Compromisso } \\
\text { Todos pela Educação, pela União Federal, com colaboração de }\end{array}$ \\
\hline
\end{tabular}




\begin{tabular}{|c|c|}
\hline 2008 & $\begin{array}{l}\text { Política Nacional } \\
\text { de Educação } \\
\text { Especial na } \\
\text { Perspectiva da } \\
\text { Educação } \\
\text { Inclusiva }\end{array}$ \\
\hline 2008 & Decreto $n^{\circ} 6.571$ \\
\hline 2009 & Decreto $n^{\circ} 6.949$ \\
\hline 2009 & Resolução $n^{\circ} 4$ \\
\hline 2011 & Decreto $n^{\circ} 7.611$ \\
\hline 2013 & Lei $n^{\circ} 12.796$ \\
\hline 2014 & Lei $n^{\circ} 13.005$ \\
\hline 2015 & Lei $n^{\circ} 13.146$ \\
\hline 2018 & Lei $n^{\circ} 13.632$ \\
\hline
\end{tabular}

Política Nacional décação Perspectiva da Educação Inclusiva

Fonte: Quadro elaborado pelos autores (2018) com base nos dados fornecidos pelo Governo Federal do Brasil.

Atual política de educação especial que apresenta, dentre outros, o cenário da educação especial no Brasil, o público a ser atendido pela nova política, bem como as diretrizes e perspectivas.

Dispõe sobre a nova política de educação especial.

Promulga a Convenção Internacional sobre os Direitos das Pessoas com Deficiência e seu Protocolo Facultativo, assinados em Nova York/2007.

Institui as diretrizes operacionais para $\bigcirc$ Atendimento Educacional Especializado, vinculado à nova política de Educação Especial.

Dispõe sobre a educação especial, o atendimento educacional especializado e dá outras providências.

Altera a Lei $n^{\circ}$ 9.394/96 ampliando o artigo 58 da LDB no que diz respeito ao entendimento da educação especial.

Plano Nacional de Educação (PNE) - Meta 4.

Institui a Lei Brasileira de Inclusão da Pessoa com Deficiência (Estatuto da Pessoa com Deficiência).

Altera Lei $n^{\circ}$ 9.394/96, modificando o Parágrafo $3^{\circ}$ do artigo 58 qualidade da educação básica.

A ampliação desses expressivos avanços contidos nos marcos regulatórios para a educação especial na perspectiva da inclusão ratifica a necessidade de investimentos na formação de educadores e no aprimoramento das práticas pedagógicas.

Segundo dados disponibilizados, em abril de 2018, pela Secretaria de Educação Continuada, alfabetização, diversidade e inclusão/ Diretoria de Políticas de Educação Especial com base no Censo Escolar da Educação Básica do INEP/2016 "apenas $5 \%$ dos docentes que atuam na educação básica possuem curso de formação continuada em educação especial" e 43\% dos que atuam em AEE possuem formação específica nessa área (MEC/SECADI/2018).

É preciso garantir a implementação das políticas públicas com efetividade de tal forma que o acesso e permanência à educação especial na perspectiva da inclusão sejam garantidas de fato, mesmo que compreendamos, alicerçados em Oliveira (1999, p. 55), que "mesmo quando tenta integrar [ou incluir], a sociedade capitalista exclui". 
Não resta dúvida de que essa significativa ampliação de matrículas traz uma série de desafios que envolvem investimentos na formação de educadores, no aprimoramento das práticas pedagógicas, na acessibilidade arquitetônica e tecnológica, na construção de redes de aprendizagem.

Com efeito, os dados do Censo Escolar da Educação Básica de 1998 a 2016 revelam significativo aumento no número de estudantes matriculados em escolas regulares, como veremos na próxima seção.

\section{POLÍtICA NACIONAL de EDUCAÇÃO ESPECIAL NA PERSPECTIVA DA EDUCAÇÃO INCLUSIVA E OS SEUS REFLEXOS NAS MATRÍCULAS}

Ao instituir em 2008 a "Política Nacional de Educação Especial na Perspectiva da Educação Inclusiva", o Ministério da Educação definiu prerrogativas que se faziam necessárias no sentido de provocar mudanças na estrutura e organização dos serviços prestados aos "estudantes com deficiência, transtornos globais do desenvolvimento e altas habilidades ou superdotação". A política defende que esses estudantes tenham o direito a frequentar a sala de aula comum e, quando necessário, recebam atendimento educacional especializado no período inverso ao da escolarização. Historicamente, essas pessoas foram excluídas do sistema educacional ou encaminhadas para escolas e classes especiais.

De fato, a "Política Nacional de Educação Especial na Perspectiva da Educação Inclusiva" apresenta metas no campo da oferta do Atendimento Educacional Especializado (AEE); na formação de professores como base de qualificação necessária aos professores do AEE e das classes comuns do ensino regular; no campo da acessibilidade arquitetônica, de transportes, mobiliários e comunicações; na base de informação e articulação intersetorial para implementação das políticas públicas.

Para implementação do AEE, institui-se as salas de recursos multifuncionais (SRM), ambientes dotados de recursos e mobiliário adaptado para ações do campo pedagógico. O AEE, conforme estabelece, deve ocorrer, prioritariamente, em salas localizadas na própria escola ou em outra 
escola de ensino regular. Esse atendimento é realizado no turno inverso ao da escolarização, não sendo substitutivo às classes comuns, podendo acontecer, também, no Centro de Atendimento Educacional Especializado (CAEE) da rede pública ou de instituições privadas/filantrópicas ou órgão equivalente dos Estados, Distrito Federal ou dos Municípios.

O Decreto $n^{\circ} 7.611$, de 17 de novembro de 2011, "Dispõe sobre a educação especial, o atendimento educacional especializado e dá outras providências". Por meio desse Decreto, o Atendimento Educacional Especializado (AEE) "deve garantir apoio especializado para eliminar as barreiras que possam obstruir o processo de escolarização de estudantes com deficiência, transtornos globais do desenvolvimento e altas habilidades ou superdotação", assegurar a Sala de Recursos Multifuncionais (SEM), formação continuada de professores para $\circ$ AEE, formação de gestores, educadores e demais profissionais para atuação na educação especial, adequações no campo de acessibilidade física e estruturação de núcleos de acessibilidade nas instituições de ensino superior.

O Decreto preconiza que o atendimento educacional especializado deve "integrar a proposta pedagógica da escola, envolver a participação da família para garantir pleno acesso e participação dos estudantes, atender às necessidades específicas [...] da educação especial, e ser realizado em articulação com as demais políticas públicas".

Para Mendes (2010, p. 18), a priorização desse apoio pedagógico apenas em forma de AEE, preferencialmente nas SRM, simplifica a oferta "(...) dos serviços de apoio que não encontra sustentação na literatura da área de Educação Especial, em termos de efetividade para atender as necessidades tão diversificadas deste alunado".

A sinalização da desvinculação com os serviços privados foi provocada pela Constituição Federal de1988 e reforçada pela Lei de Diretrizes e Bases da Educação, LDB/1996, porém não efetivada nas duas primeiras políticas implementadas. O termo "preferencialmente" adotado na CF/1988 e LDB/1996 em relação à destinação de matrícula de pessoas com 
deficiência na rede regular de ensino era assumido pelas instituições privadas como sopro de continuidade da oferta de ensino.

A questão, porém, é que o termo novamente é exposto pela nova política, no tocante ao AEE, a ser ofertado "preferencialmente na rede regular de ensino, podendo ser realizado por meio de convênios com instituições especializadas, sem prejuízo do sistema educacional inclusivo" (BRASIL, 2008a, p. 7, grifo nosso).

Para que as instituições especializadas não tivessem prejuízo com a mudança no modelo proposto, de escola especial para AEE, o Decreto $n^{\circ} 7$. $611 / 2011$ instituiu a dupla matrícula, resguardando duplo recurso per capita, ou seja, recebe recurso do governo federal tanto a instituição pública que promove o ensino regular às pessoas com deficiência quanto à instituição privada que realiza O AEE: "O Poder Público estimulará O acesso ao atendimento educacional especializado de forma complementar ou suplementar ao ensino regular, assegurando a dupla matrícula nos termos do art. 9-A do Decreto n. 6.253, de 13 de novembro de 2007" (art. 4) (BRASIL, 2007; 2011).

Viegas (2014) destaca que o Decreto $n^{\circ} 7.611 / 2011$ parece ser uma resposta às manifestações das instituições privadas quanto ao duplo financiamento de matrícula, que até então as matrículas tinham sua centralidade nas escolas regulares. Desse modo, O AEE pode ocorrer em diversos espaços, sendo que, em cada um deles, irá caracterizar sua organização pedagógica, ainda que, segundo a legislação, as ações do AEE devam constar no projeto político-pedagógico da escola.

Assim, conforme 0 Art. 14, do Decreto $n^{\circ} 7.611 / 2011$, admite a distribuição dos recursos do FUNDEB para as matrículas "efetivadas na educação especial oferecida por instituições comunitárias, confessionais ou filantrópicas sem fins lucrativos, com atuação exclusiva na educação especial, conveniadas com o Poder Executivo competente".

Conforme apresentado, historicamente, a educação especial tem sido marcada por um viés muito direcionado ao assistencialismo, assim como a uma vertente médico-pedagógica, o que continua presente na atuação 
dos professores, no desenvolvimento das atividades do AEE, na SRM e de maneira ainda mais forte nos CAEE, que, por sua própria constituição e significação nas instituições especializadas, trazem consigo as características desse antigo modelo.

A questão, porém, é que, mesmo não cessando, as instituições privadas têm o seu contingente sendo reduzido. Como reflexo, a migração externada pela nova política de educação especial, além de ampliar e incentivar novas matrículas nas escolas da rede regular de ensino, imprime uma mudança drástica no cenário de matrículas de alunos da educação especial em escolas da rede regular de ensino. Tal fator pode ser, nitidamente, notado pela observância do Gráfico 1. Observamos também que entre 2008 e 2016 as matrículas desses estudantes em escolas regulares subiram de 375.775 para 796.486 .

Gráfico 1 - Série histórica de matrículas de educandos com necessidades especiais

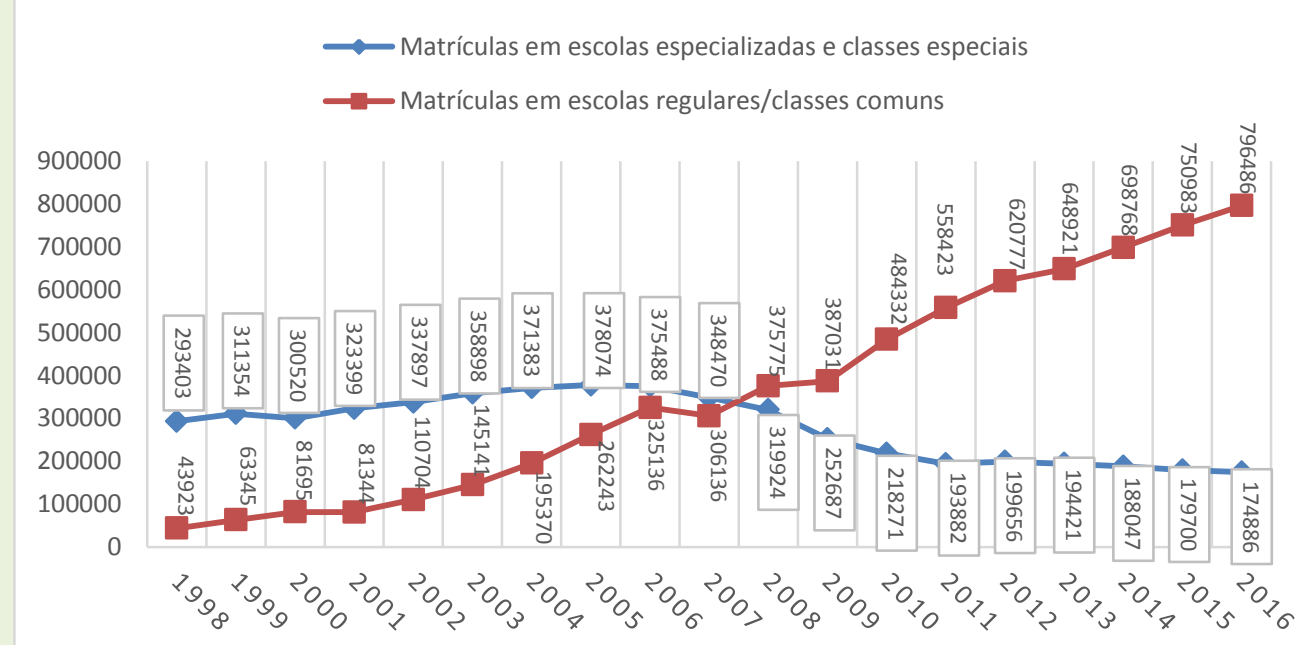

Fonte: Gráfico elaborado pelos autores (2018) com base no Censo escolar (INEP) de 1998 a 2016.

A curva de matrículas em escolas especializadas e classes especiais que se apresentava em uma crescente até o ano de 2006, a partir da instituição da nova política de educação especial, passa a apresentar sucessivas quedas de matrícula, ao tocante que, de modo oposto, no 
mesmo marco temporal, a curva das matrículas em escolas da rede regular ascendeu significativamente.

No dia $1^{\circ}$ de junho de 2018, a Federação Nacional das Apaes (FENAPAES) divulgou um "Manifesto da rede Apae pela atualização da política de Educação Especial no Brasil", baseado no ordenamento jurídico brasileiro, defendendo os direitos das pessoas com deficiência à educação, "especialmente, aquelas com deficiência intelectual e múltipla em situação de alta complexidade, cuja intensidade de apoios humanos, técnicos, tecnológicos e materiais". Segundo apresenta, os apoios "são melhor e suficientemente ofertados nas escolas especiais" e cuja "alternativa está legalmente prevista na própria LDBEN, na Resolução CNE/CEB n. 2/2001 e no Plano Nacional de Educação 2014-2024". E reclamam que

Tanto as escolas especiais como os CAEEs mantidos pelas Apaes, estão amparados, legalmente, a fazerem jus ao apoio técnico e financeiro ofertado pelo poder público, conforme o Art. 60 da LDBEN, a Lei do Fundeb, a Lei $n^{\circ} 11.494 / 2007$, o Decreto 7611/2011. Ocorre que essas instituições têm experimentado a negação desses direitos; têm sofrido pressão escusa para tornarem-se CAEEs; têm vivenciado retaliações, quando se recusam a mudança de sua identidade institucional, entre outras ameaças a sua existência. Essa realidade é experimentada de diferentes formas: (a) grande número de Estados e Municípios dificilmente se comprometem com o repasse dos recursos do Fundeb; (b) algumas unidades apaeanas não recebem, sequer, as parcelas que lhes são devidas; (c) mesmo unidades apaeanas que trocaram sua identidade de escola especial para Centro de Atendimento Educacional Especializado, não recebem os devidos recursos financeiros para manter a oferta do Atendimento Educacional Especializado. Tal situação se agrava, quando o Censo Escolar, ano após ano, não retrata a realidade, devido à insuficiência e/ou incompatibilidade de campos para lançamento de dados que registrem os serviços e atendimento oferecidos (FENAPAES, 2018).

Conforme Muller e Surel (2002, p. 14) nos orientam, a política pública é formada, inicialmente, por um conjunto de medidas concretas que constituem a substância "visível" da política e todas as decisões e ações constituem "um conjunto extremamente heteróclito que põe em jogo numerosos atores pertencentes a múltiplas organizações, públicas ou privadas, e que intervêm em diversos níveis". 
A questão que se coloca, então, é a coerência das políticas públicas em que, por vezes, os fins governamentais permanecerão fluidos, até ambíguos. Isso implica que os objetivos da ação pública não são dados, mas devem constituir o objeto de um trabalho de identificação e reconstrução pelo pesquisador (MULLER; SUREL, 2002).

As questões levantadas pela FENAPAE pressupõem um movimento político historicamente constituído e devem ser melhor estudadas, aprofundadas e compreendidas - daí a presunção da presença do pesquisador -, de tal forma que sejamos capazes de reconstruirmos não somente a estrutura normativa das políticas, mas o contexto histórico-social a que responde.

Quando nossa análise se desloca para o perfil atual dos educandos da educação especial que passaram a compor a rede regular de ensino, temse, no Gráfico 2, uma distribuição das matrículas por etapas e modalidades de ensino.

Gráfico 2 - Matrículas na Educação Especial em classes comuns do ensino regular -2016

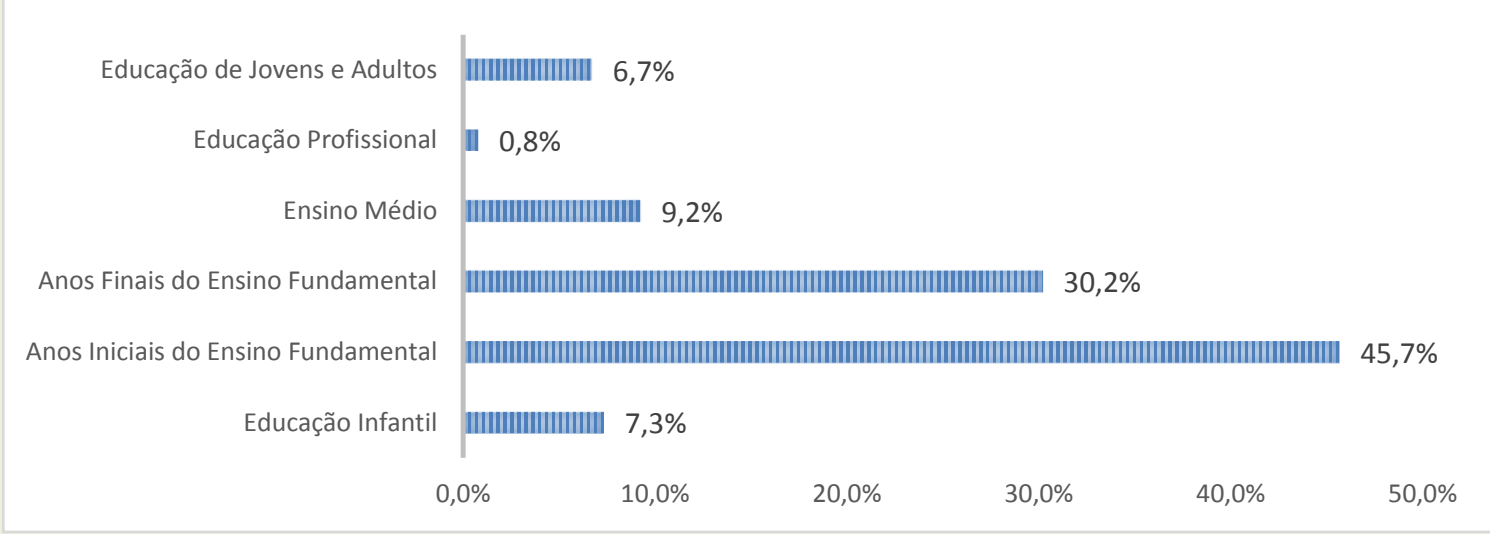

Fonte: Gráfico elaborado pelos autores (2018) com base no Censo escolar (INEP, 2016).

Destoando dos demais estados brasileiros, os dados do Censo Escolar nos mostram que, no Paraná, $18,2 \%$ dos municípios possuem menos da metade dos educandos com necessidades especiais matriculados na Educação Básica na faixa etária de 4 a 17 anos, conforme se observa no 
Mapa 1. Destacam, em termos de maior variação de concentração de faixa etária, os estados de São Paulo, Minas Gerais e Paraná (MEC/INEP, 2016).

Mapa 1 - Percentual de alunos matriculados de 4 a 17 anos com necessidades especiais incluídos em classes comuns por município brasileiro 2016

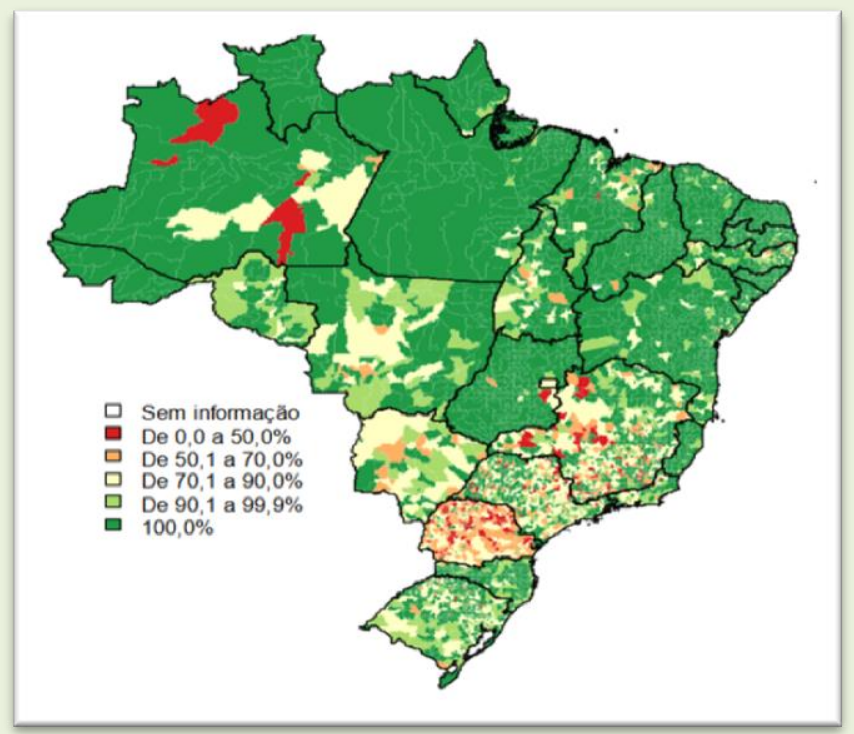

Fonte: Censo escolar (INEP, 2016).

Elaboração: Notas estatísticas, Censo Escolar (2016 p. 11).

É importante compreender que, do ponto de vista histórico, pessoas com deficiência matriculadas nas escolas especiais, principalmente deficiência intelectual, como apresenta Marques (2001), são retidas nas séries iniciais do Ensino Fundamental por várias décadas sob o argumento de que não alcançavam as competências mínimas desejadas para a promoção em níveis educacionais mais elevados.

A partir da nova política de educação especial implementada em 2008, tais alunos tiveram que migrar do ensino especial para escolas comuns da rede regular de ensino, porém, pela distorção idade/série elevada, passaram a ser matriculados na modalidade de Educação de Jovens e Adultos (que era prioritariamente realizada no turno noturno, passando, desde então, a também ser ofertada no turno matutino).

O Gráfico 3, seguinte, mostra a representatividade da deficiência intelectual em relação ao público da educação especial. 
Gráfico 3 - Matrícula de educandos em Classes Comuns - Ensino Regular por tipo de necessidade especial - 2016

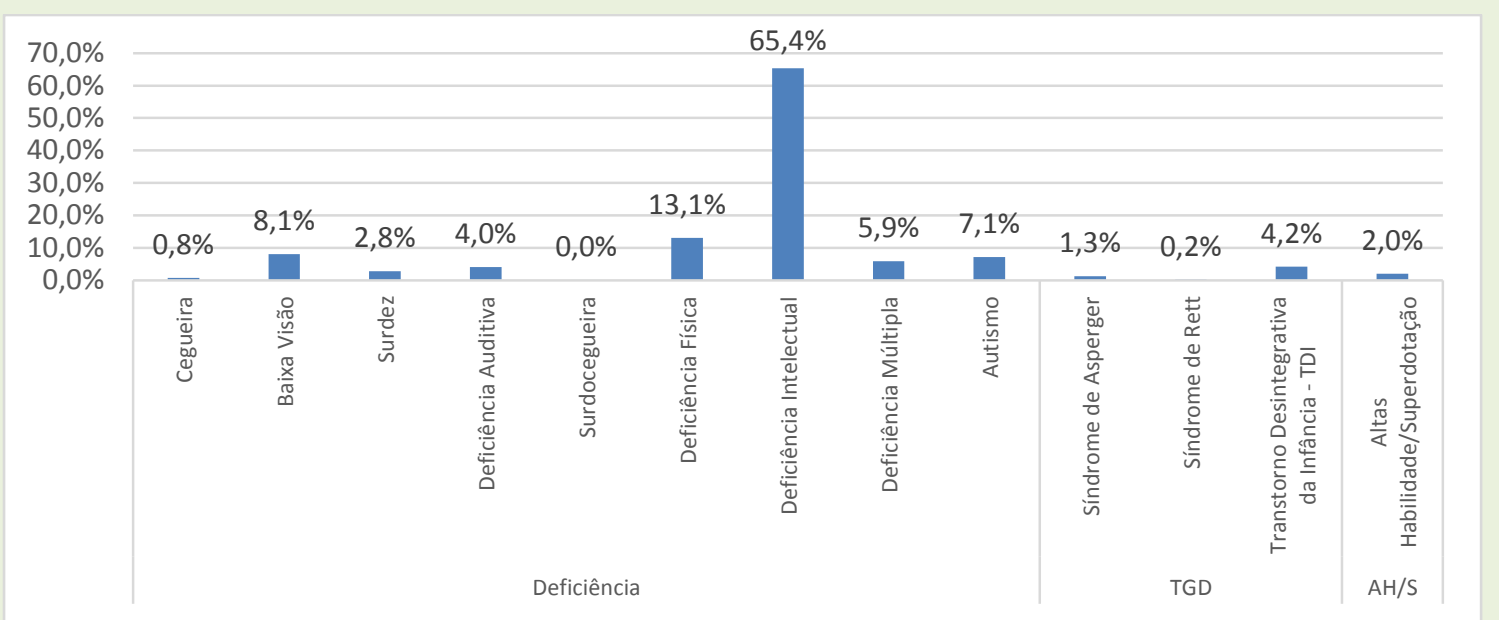

Nota: $\mathrm{TGD}=$ Transtornos Globais do Desenvolvimento; $\mathrm{AH} / \mathrm{S}=$ Altas Habilidades/Superdotação

Fonte: Gráfico elaborado pelos autores (2018) com base no Censo escolar (INEP, 2016).

Sobre a concentração majoritária de matrículas de alunos públicoalvo da educação especial com idade igual ou inferior a 14 anos (Gráfico 4 e Mapa 1), em grande parte com deficiência intelectual (Gráfico 4), é possível observar os dados sobre olhar da EJA que, historicamente, tem se constituído com público distinto ao da educação especial.

Gráfico 4 - Faixa etária dos educandos da Educação Especial matriculados em classes comuns do ensino regular

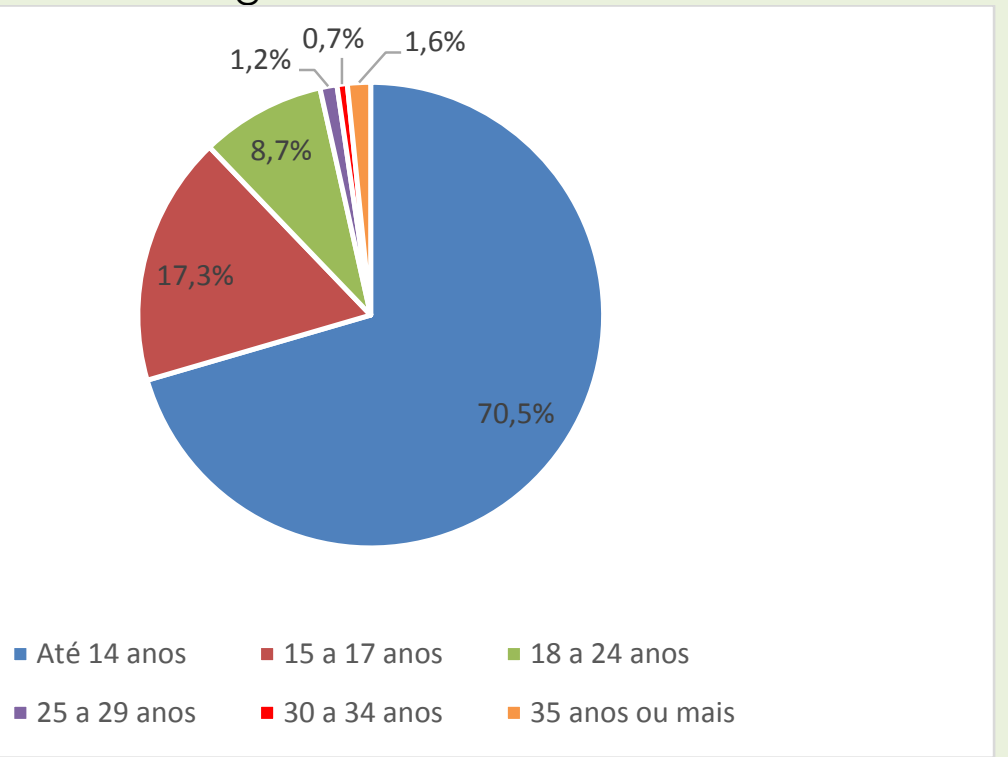

Fonte: Gráfico elaborado pelos autores (2018) com base no Censo escolar (INEP, 2016). 
O Observatório do Plano Nacional de Educação (PNE), Lei $n^{\circ}$ 13.005/2014, reconhece que "não há dados para o monitoramento" da meta 4, que trata da Educação Especial/Inclusão. Registra o Observatório que "as pesquisas e o Censo do IBGE não levantam informações completas que permitam diagnosticar a situação. Tal descompasso é sintoma do descaso histórico em relação ao tema. Indicadores auxiliares ajudam a traçar um panorama geral da situação".

Nosso esforço neste trabalho foi colaborar com o debate e trazer alguns dados oficiais que possibilitem suscitar a reflexão do cenário das políticas públicas para educação especial.

\section{CONSIDERAÇÕES FINAIS}

Qualquer resposta que se busque acerca das políticas públicas implementadas por uma ação governamental precisa levar em conta que estudar a ação do Estado não consiste, simplesmente, em enxergá-lo como um aparelho político administrativo ou com base apenas nos aspectos normativos e legais, bem como pensar que para haver política pública, todas as medidas em questão devem ser reunidas num quadro normativo e cognitivo perfeitamente coerente. Se tal fosse o caso, isso significaria dizer que, sem dúvida, não existiria jamais "verdadeira" política, como nos alertam Muller e Surel (2002).

A análise das políticas públicas no geral e das políticas educacionais em particular não formam um todo coerente. Outro impasse teórico e metodológico que precisa ser vencido é negar qualquer racionalidade da ação pública, em vista das múltiplas incoerências que ela manifesta. Para sair dessa dificuldade, o trabalho de análise deve esforçar-se para colocar à luz as lógicas de ação e em ação as lógicas de sentido no processo de elaboração e de implementação das políticas (MULLER; SUREL, 2002; SOUZA, SOUSA, 2017).

Assim, buscar o cenário das políticas públicas para educação especial, na perspectiva da inclusão no Brasil de hoje, é tomar-se 
consciência do caráter intrinsecamente contraditório da política. Defendese inclusão, mas não se garante que ela se efetive, vide o sentido da promulgação da Emenda Constitucional 95/2016, que institui o "Novo Regime Fiscal" que congela os gastos federais pelos próximos 20 anos, sendo atualizados pela inflação do ano anterior com base na variação do Índice de Preços ao Consumidor Amplo (IPCAP). Os estudos revelam que os recursos para educação e saúde diminuirão.

Nesse passo, como garantir o acesso e permanência da população com deficiência, transtornos globais do desenvolvimento e altas habilidades ou superdotação, à educação básica e ao atendimento educacional especializado, preferencialmente na rede regular de ensino com qualidade?

A garantia de sistema educacional inclusivo, com salas de recursos multifuncionais bem equipadas, classes, escolas ou serviços especializados, públicos ou conveniados com professores especializados, necessita de recursos financeiros para sua efetivação.

Nesse sentido, o cenário ora apresentado nos parece nebuloso, deixando claro que embora tenhamos avançado no que diz respeito às políticas públicas, na prática, é possível constatar ainda a existência de uma inclusão-excludente, tornando-se explícita as situações de descaso em relação à educação dos alunos público-alvo da educação especial.

Com efeito, a análise empreendia neste artigo mostra-nos que precisamos ter um olhar crítico sobre as políticas de inclusão, considerando que elas estão permeadas por relações de controle e dominação, ajustando-se, portanto, às dinâmicas de poder e saber de seu tempo.

Ademais, num momento em que se fala tanto de inclusão, em que se salienta a inclusão como forma de transposição de barreiras sociais e segregadoras, em que se discute a importância de uma sociedade que considera todos os seus membros como cidadãos legítimos, em que se discute a questão das diferenças, faz-se necessário atentar para a necessidade de maiores investimentos na formação dos educadores e no aprimoramento das práticas pedagógicas. 
Por fim, embora reconheçamos as dificuldades ou impossibilidades de identificar todos os sentidos que circulam nas políticas públicas de inclusão, esperamos que as discussões e análises apresentadas neste artigo, possam, de alguma maneira, convidar-nos a pensar sobre os mecanismos que contribuem para acentuar as desigualdades estabelecidas historicamente em relação aos alunos, principalmente, em nosso recorte de estudo, aos que constituem o público-alvo da educação especial.

\section{REFERÊNCIAS}

ALMEIDA, D. B.; TEIXEIRA, R. A. G. O contexto educacional complexo e diverso a partir de uma análise interpretativa dos aspectos legais que subsidiam propostas educativas inclusivas. In: LIBÂNEO, J. C.; SUANNO, M. V. R. (Org.). Didática e Escola em uma sociedade complexa. Goiânia: CEPED, 2011.

BRASIL. Constituição da República Federativa do Brasil. Brasília, DF: Senado Federal: Centro Gráfico, 1988. 292 p.

BRASIL. Decreto n 3.298, de 20 de dezembro de 1999. Regulamenta a Lei n. 7.853, de 24 de outubro de 1989, dispõe sobre a Política Nacional para a Integração da Pessoa Portadora de Deficiência, consolida as normas de proteção, e dá outras providências. Diário Oficial [da] República Federativa do Brasil, Poder Executivo, Brasília, DF, 21 dez. 1999.

BRASIL. Decreto n 3.956 , de 8 de outubro de 2001. Promulga a Convenção Interamericana para a Eliminação de Todas as Formas de Discriminação contra as Pessoas Portadoras de Deficiência. Diário Oficial [da] República Federativa do Brasil, Poder Executivo, Brasília, DF, 9 out. 2001.

BRASIL. Decreto $n^{\circ} 72.425$, de 3 de Julho de 1973. Cria o Centro Nacional de Educação Especial (CENESP), e dá outras providências. Diário Oficial [da] República Federativa do Brasil, Poder Executivo, Brasília, DF, 4 jul. 1973.

BRASIL. Lei n. 7.853, de 24 de outubro de 1989. Dispõe sobre o apoio às pessoas portadoras de deficiência, sua integração social, sobre a Coordenadoria Nacional para Integração da Pessoa Portadora de Deficiência - Corde, institui a tutela jurisdicional de interesses coletivos ou difusos dessas pessoas, disciplina a atuação do Ministério Público, define crimes, e dá outras providências. Diário Oficial [da] República Federativa do Brasil, Poder Executivo, Brasília, DF, 25 out. 1989. 
BRASIL. Lei n 13.005, de 25 de junho de 2014. Aprova o Plano Nacional de Educação - PNE e dá outras providências. Diário Oficial [da] República Federativa do Brasil, Poder Executivo, Brasília, DF, 26 jun. 2014.

BRASIL. Lei n 4.024/1961, de 20 de dezembro de 1961. Fixa as Diretrizes e Bases da Educação Nacional. Diário Oficial [da] República Federativa do Brasil, Poder Executivo, Brasília, DF, 17 dez. 1962.

BRASIL. Lei n 8.069, de 13 de julho de 1990. Dispõe sobre o Estatuto da Criança e do Adolescente Diário Oficial [da] República Federativa do Brasil, Poder Executivo, Brasília, DF, 16 jul. 1990.

BRASIL. Lei n 9.394, de 20 de dezembro de 1996. Estabelece as diretrizes e bases da educação nacional. Diário Oficial [da] República Federativa do Brasil, Poder Executivo, Brasília, DF, 23 dez. 1996.

BRASIL. Lei no 10.172, de 9 de janeiro de 2001. Aprova o Plano Nacional de Educação e dá outras providências. Diário Oficial [da] República Federativa do Brasil, Poder Executivo, Brasília, DF, 10 jan. 2001.

BRASIL. Ministério da Educação. Secretaria de Educação Continuada, Alfabetização, Diversidade e Inclusão. Diretoria de Políticas de Educação Especial. Atualização da política nacional de educação especial. Abr. 2018. 21 slides. Apresentação em PowerPoint. Brasília: MEC/Secadi, 2018. BRASIL.

BRASIL. n. 7.611 , de 17 de novembro de 2011. Dispõe sobre a educação especial, o atendimento educacional especializado e dá outras providências. Diário Oficial [da] República Federativa do Brasil, Poder Executivo, Brasília, DF, 18 nov. 2011.

BUENO, J. G. S. Educação especial brasileira: integração/segregação do aluno diferente. São Paulo: EDUC, 1993.

CONSELHO NACIONAL DE EDUCAÇÃO. Câmara de Educação Básica. Resolução CNE/CEB 2/2001. Diário Oficial da União, Brasília, 14 de setembro de 2001. Seção 1E, p. 39-40

Decreto $\mathrm{n}^{\circ}$ 1.428, de 12 de Setembro de 1854. Crea nesta Côrte hum Instituto denominado Imperial Instituto dos meninos cegos. Disponível em: http://www2.camara.leg.br/legin/fed/decret/1824-1899/decreto-1428-12setembro-1854-508506-publicacaooriginal-1-pe.html>. Acesso em: 21 jul. 2018.

FEDERAÇÃO NACIONAL DAS APAES (FENAPAES). Manifesto da rede Apae pela atualização da política de educação especial no Brasil. Disponível em:< https://apaebrasil.org.br/noticia/manifesto-da-rede-apae-pela-atualizacaoda-politica-de-educacao-especial-no-brasil>. Acesso em: 21 jul. 2018. 
INEP - INSTITUTO NACIONAL DE ESTUDOS E PESQUISAS EDUCACIONAIS ANÍSIO TEIXEIRA. Censo Escolar da Educação Básica 2016: Notas Estatísticas. INEP, Ministério da Educação, Brasília, 2017, 28 p.

JANNUZZI, G. de M. Educação do deficiente no Brasil: dos primórdios ao início do século XXI. 3. ed. Revista. São Paulo: Autores Associados, 2012.

LUNARDI, M. L. Inclusão/Exclusão: duas faces da mesma moeda. Revista CEESP, n. 18. 2001. Disponível em:

<wWw.ufsm.br/revista/ceesp/2001/02/a3htm>. Acesso em: 21 jul. 2018.

MARQUES, L. P. Professores de alunos com deficiência mental: concepções e práticas pedagógicas. Juiz de Fora - MG: UFJF, 2001.

MARTINS, L. de A. R. História da educação de pessoas com deficiência: da antiguidade ao início do século XXI. São Paulo: Mercado de Letras, 2015.

MAZZOTTA, M. J. da S. Educação Especial no Brasil: história e políticas públicas. 5. ed. São Paulo: Cortez, 2005.

MENDES, E. G.; CIA, F. Observatório Nacional de Educação Especial: estudo em rede nacional sobre as salas de recursos multifuncionais nas escolas comuns. Projeto de Pesquisa - Observatório da Educação, Edital No 38/2010 CAPES/INEP. Brasília, 2010.

MULLER, P.; SUREL, Y. Análise de políticas públicas. Pelotas: EDUCAT, 2002. Disponível em: <http://www.abavaresco.com.br/images/stories/0203.pdf> Acesso em: 21 jul., 2018.

OLIVEIRA, F. de. A Questão do Estado. Cadernos ABONG, n. 8, p. 7-8. São Paulo, 1995.

SOUZA, L. M. de; SOUSA, A. da S. Q. Avaliação de políticas públicas e avaliação de educação. Curitiba: CRV, 2017.

TEIXEIRA, R. A. G. Matemática Inclusiva? O processo ensino-aprendizagem de matemática no contexto da diversidade. 2010. 424 f. Tese (Programa de Pósgraduação em Educação) - Faculdade de Educação, Universidade Federal de Goiás, Goiânia, 2010.

UNESCO. Declaração de Salamanca e Linha de Ação sobre Necessidades Educativas Especiais. Brasília: CORDE, 1994.

UNESCO. Declaração Mundial sobre Educação para Todos: plano de ação para satisfazer as necessidades básicas de aprendizagem. Jomtiem:

Tailândia, 1990. 
VIEGAS, L. T. A reconfiguração da Educação Especial e os espaços de Atendimento Educacional Especializado: análise da constituição de um centro de atendimento em Cachoerinha/RS. 325f. Tese (Programa de Pósgraduação em Educação) - Faculdade de Educação, Universidade Federal do Rio Grande do Sul, Porto Alegre, 2014.

Recebido em: Janeiro de 2018

Aprovado em: Junho de 2018 